\title{
Correction to: Managing Student Behavior in a Middle School Special Education Classroom Using CW-FIT Tier 1
}

\author{
Robyn K. Orr ${ }^{1} \cdot$ Paul Caldarella $^{1}$ (D) $\cdot$ Blake D. Hansen ${ }^{1} \cdot$ Howard P. Wills ${ }^{2}$
}

Published online: 8 February 2020

๑) Springer Science+Business Media, LLC, part of Springer Nature 2020

\section{Correction to: Journal of Behavioral Education https://doi.org/10.1007/s10864-019-09325-w}

The original version of this article unfortunately contained a mistake in the funding information. The IES grant number was listed incorrectly. It should be R324A160279, not R0302677.

Publisher's Note Springer Nature remains neutral with regard to jurisdictional claims in published maps and institutional affiliations.

The original article can be found online at https://doi.org/10.1007/s10864-019-09325-w.

Paul Caldarella

paul_caldarella@byu.edu

Robyn K. Orr

robyn.k.orr@gmail.com

Blake D. Hansen

blake_hansen@byu.edu

Howard P. Wills

hpwills@ku.edu

1 Center for the Improvement of Teacher Education and Schooling, Brigham Young University, 149 MCKB, Provo, UT 84602, USA

2 University of Kansas, 444 Minnesota Ave \#300, Kansas City, KS 66101, USA 